\title{
A práxis do psicólogo no contexto da assistência social
}

\author{
The praxis of the psychologist in \\ the context of social assistance
}

\section{Nívia Arlete Souza Duarte ${ }^{1}$ (1) Silvia Virginia Coutinho Areosa² (1)}

1'Autora para correspondência. Escola de Saúde Pública (Porto Alegre). Rio Grande do Sul, Brasil. nivia.duarte@hotmail.com ${ }^{2}$ Universidade de Santa Cruz do Sul (Santa Cruz do Sul). Rio Grande do Sul, Brasil. sareosa@unisc.br

\begin{abstract}
RESUMO | A Assistência Social surge como um campo de trabalho interdisciplinar executado principalmente por equipes multidisciplinares em que o papel da Psicologia se destaca. Este artigo busca refletir sobre a atuação do psicólogo no Sistema Único de Assistência Social (SUAS), através de uma pesquisa qualitativa, da qual participaram nove psicólogos que trabalham nos CRAS (Centro de Referência de Assistência Social) e CREAS (Centro de Referência Especializado de Assistência Social) de dois municípios do Rio Grande do Sul. Os dados foram coletados por meio de entrevistas semiestruturadas, e sua análise norteada pela análise de conteúdo de Bardin (2004). Emergiram quatro categorias de análise: atuação do psicólogo na assistência social, percepção dos profissionais sobre os usuários, percepção dos profissionais sobre o trabalho, atravessamentos no trabalho. Os resultados apontam que a prática dos profissionais ainda é permeada pela visão da clínica tradicional, hegemônica na formação dos psicólogos. Contudo, muitos deles refletem criticamente diante de seu trabalho, compreendendo que é preciso construir espaços para pensar além e modificar suas práticas.
\end{abstract}

PALAVRAS-CHAVE: Prática profissional. Psicologia Social. Assistência Social.

\begin{abstract}
The Social Assistance emerges as a field of interdisciplinary work performed mainly by multidisciplinary teams in which the role of Psychology stands. This article aims to reflect on the performance of the psychologist in the Single System of Social Assistance (SUAS), through a qualitative research, which was attended by nine psychologists who work in the CRAS (Center of reference for Social Assistance) and CREAS (Reference Center of expertise for Social Assistance) of two municipalities in the state of Rio Grande do Sul. The data were collected through a semi-structured interview, and its analysis guided by the analysis of content of Bardin (2004). Four categories of analysis emerged: performance of psychologist in social assistance, perception of professionals about users, perception of professionals about the work, crossings at work. The results point out that the practice of professionals is still permeated by the vision of the traditional clinic, hegemonic in the formation of psychologists. However, many of them reflect critically on their work, understanding that it is necessary to build spaces to think beyond and modify their practices.
\end{abstract}

KEYWORDS: Professional practice. Social Psychology. Social Assistance. 


\section{Introdução}

A Assistência Social tem sua existência muito antes da criação do Sistema Único de Assistência Social (SUAS), pois, o povo brasileiro já necessitava de amparo em épocas longevas, como no Brasil Colonial. Conforme destacam Gomes e Gonçalves (2018), o modelo socioassistencial passou por muitas fases, considerado inicialmente como auxílio aos pobres, associando-se às questões religiosas, também foi visto como uma prática higienista, que controla e oprime as famílias, indivíduos e comunidades. Portanto, se consolidou enquanto prática assistencialista e não como política pública, "seu objetivo não era atender as necessidades ou muito menos os direitos da população, mas perpetuar posições sociais" (Conselho Federal de Psicologia [CFP], 2012, p. 30).

A partir das mudanças sociais que ocorreram no ano de 1988 por meio da Constituição Federal, a Assistência Social se fortalece como política pública não contributiva, sendo direito de todo cidadão que dela necessitar. Juntamente à Saúde e Previdência, a Assistência Social compõe o tripé da seguridade social, essa união tem como objetivo o desenvolvimento de um estado de bem estar social (Silva, Pereira \& Tavares, 2018). Deste modo, começa-se a pensar a Assistência pelo viés da cidadania e da garantia de direitos, retirando o enfoque da noção de caridade (Cruz \& Guareschi, 2012a).

Cabe destacar que apenas no ano de 2004 a Política Nacional de Assistência Social (PNAS) foi regulamentada e, logo após, em 2005 o SUAS foi implementado. A Assistência Social possui como público prioritário as pessoas que estão em situações de vulnerabilidade social e riscos. A vulnerabilidade está mais relacionada a questões concretas de vida, como por exemplo às condições socioeconômicas. Já os riscos são produzidos de forma situacional, por meio de condições provisórias e momentâneas, como violências e negligências (Silva, Pereira \& Tavares, 2018).

O SUAS organiza a oferta de seus serviços de acordo com a complexidade da situação em: Proteção Social Básica e Proteção Social Especial. A primeira possui como foco prevenir as vulnerabilidades, riscos sociais e a violação de direitos, para promover a autonomia dos sujeitos e fortalecer seus vínculos familiares e comunitários. Através do Centro de Referência de Assistência Social (CRAS) são instrumentalizadas as ações de prevenção (Brasil, 2011a).
A Proteção Social Especial atua em casos complexos, nos quais já houve a violação de direitos, o rompimento dos vínculos e a exposição ao risco. Assim, trabalha com vistas ao fortalecimento e proteção do sujeito diante do enfrentamento dessas dificuldades, ressaltando as suas potencialidades. Esta é dividida em: Proteção Social Especial de Média Complexidade e Alta Complexidade. O CREAS é um dos serviços ofertados pela Proteção Especial de Média Complexidade (Brasil, 2011a).

Uma pesquisa realizada por Macedo et al. (2011), feita com dados secundários do Cadastro Nacional do Suas (CadSuas), verificou a situação da Assistência Social no país e mostrou que dos 5.565 municípios 4.743 tinham unidades do CRAS, o que totalizava 7.607 serviços de proteção social básica no território brasileiro. Os autores ainda referem que dos 8.079 psicólogos que atuavam no SUAS, 6.022 trabalhavam no CRAS, sendo que mais de $90 \%$ desses profissionais atuavam em municípios do interior.

Neste contexto, a Psicologia encontra na Assistência Social um amplo campo de atuação. Nos estudos realizados acerca das contribuições dos psicólogos nos serviços do SUAS, o que prevalece é o entendimento de que é preciso abandonar as práticas assistencialistas e repressivas que originaram a Assistência Social, as quais culpabilizam os sujeitos. Deste modo, será realmente possível garantir os direitos dos cidadãos e promover a autonomia e protagonismo dos mesmos. (Macêdo et al., 2018).

A Psicologia na perspectiva do fortalecimento dos vínculos destaca um olhar e uma escuta diferenciada. A partir de seus variados modelos teóricos e metodológicos, a área permite entender as diferentes realidades e contextos sociais, com uma visão crítica de mundo e assim, contribui com as práticas da Assistência Social (CFP, 2016).

A atuação do psicólogo deve se pautar pelo viés da garantia de direitos, da proteção social e do enfretamento às violências e desigualdades, distinguindo-se de um trabalho psicoterapêutico e psicodiagnóstico, uma vez que, estas práticas não devem ser realizadas neste âmbito. Ademais, é fundamental a construção de estratégias que estimulem a reflexão dos sujeitos diante de seus conflitos, tornando-os ativos no processo de transformação de sua condição social (CFP, 2016). 
No entanto, observa-se ainda uma prática psicológica pautada nos pressupostos positivistas que embasaram o nascimento da Psicologia enquanto ciência e profissão. De acordo com Macêdo et al. (2018) e Rechtman e Bock (2019), existe um predomínio de concepções individualizantes e descontextualizadas da realidade de vida dos sujeitos assistidos pela Assistência Social, fato que representa a dicotomia objetividade-subjetividade. Tal perspectiva está associada a uma visão de clínica tradicional, que relaciona a subjetividade somente aos aspectos individuais, desconsiderando o fato de ser ela uma construção social e histórica, um processo dinâmico e ao mesmo tempo singular e único (Reis \& Guareschi, 2013; Sundfeld, 2010).

A Psicologia enfrenta muitos desafios em sua inserção no SUAS, que são justificados pelo seu contexto histórico de criação e formação dos profissionais. Deste modo, torna-se necessário elucidar o lugar da prática psicológica no contexto da Assistência Social, faz-se importante problematizar suas contribuições e práticas, uma vez que, o papel do psicólogo nesta política transcende os saberes psicológicos aprendidos ao longo de sua formação profissional, em que emergem situações complexas. Assim, o artigo se propõe a refletir a prática profissional de psicólogos inseridos nos serviços CRAS e CREAS no interior do Rio Grande do Sul a fim de explicitar suas ações e intervenções junto a política de assistência social.

\section{Método}

O estudo aqui apresentado é uma pesquisa qualitativa e transversal, de caráter exploratório descritivo, que tem como objeto de análise a atuação do psicólogo no SUAS. A pesquisa qualitativa possui como pressuposto que o pesquisador não é neutro, seus julgamentos e valores interferem na pesquisa, seu trabalho é perpassado por questões subjetivas, crenças e significados, e transcende a quantificação das realidades (Silveira \& Córdova, 2009). Participaram desta pesquisa nove psicólogos, sendo que desses, quatro trabalhavam nos CRAS (Centro de Referência de Assistência Social) e cinco nos CREAS (Centro de Referência Especializado de Assistência Social) de dois municípios do Vale do Rio Pardo no Rio Grande do Sul. Os dois municípios contavam com apenas um CREAS. O critério de inclusão dos participantes foi a delimitação do período de trabalho nos locais de no mínimo seis meses. Como critério de exclusão foi considerada a recusa na participação, bem como, os profissionais que não quisessem assinar o TCLE.

A coleta de dados foi realizada no período de março a junho de 2018 e ocorreu por meio de uma entrevista semiestruturada contendo oito questões norteadoras relacionadas à percepção dos profissionais sobre o papel do psicólogo na Assistência Social, a maneira como ocorrem os atendimentos, a percepção dos profissionais sobre os usuários dos serviços, bem como, o modo de organização e o funcionamento do trabalho. A pesquisa cumpriu com todos os critérios éticos, sendo aprovada pelo Comitê de Ética da Universidade de Santa Cruz do Sul (CAAE no 81355817.2.0000.5343). As entrevistas foram previamente agendadas por meio de contato telefônico realizado com todos os participantes e após o consentimento voluntário e assinatura do Termo de Consentimento Livre e Esclarecido em duas vias. As entrevistas foram realizadas no local de trabalho dos psicólogos, em apenas um encontro com duração de cerca de 40 minutos. Conforme concordância espontânea dos psicólogos, as entrevistas foram gravadas e posteriormente transcritas em sua íntegra para análise.

A análise dos dados foi feita através da técnica de análise de conteúdo de Bardin (2004), que é concebida como um conjunto de técnicas relacionadas à análise das comunicações, significados e significantes. Ela também é conceituada como "uma técnica de investigação que através de uma descrição objectiva, sistemática e quantitativa do conteúdo manifesto das comunicações, tem por finalidade a interpretação destas mesmas comunicações" (Bardin, 2004, p. 31). Assim, após a leitura exaustiva das entrevistas e classificação das falas relevantes, emergiram quatro categorias de acordo com os objetivos desta investigação: atuação do psicólogo na Assistência Social, percepção dos profissionais sobre os usuários, percepção dos profissionais sobre o trabalho, atravessamentos no trabalho.

\section{Resultados e Discussão}

\section{Atuação do Psicólogo na Assistência Social}

Esta categoria abrange as falas referentes ao papel do psicólogo no contexto da Assistência Social, o que reflete a prática e a intervenção profissional. 
Os entrevistados apontaram a garantia de direitos, o fortalecimento dos vínculos, a prevenção das vulnerabilidades, a proteção social e o empoderamento dos usuários como eixos norteadores da atuação do psicólogo. Também citaram estratégias para efetivação desses eixos, como a escuta, orientação, encaminhamentos e articulação com a rede.

"Primeiro, eu acho que enquanto garantia né, o que vai preconizar a própria política assim né, que é dessa garantia de direitos, que é na lógica então, de fortalecer os vínculos, de poder trabalhar com a prevenção e dar conta de algumas vulnerabilidades e riscos [...]." (Psicólogo 8, comunicação pessoal).

"Acho que o papel do psicólogo na assistência tem a ver com isso assim, buscar uma orientação, ajudar, vamos dizer assim, um trabalho que eles possam se organizar, se independizar, ser protagonista das suas mudanças, o que eles também têm expectativas de mudanças, desejos de mudanças." (Psicólogo 4, comunicação pessoal).

Observa-se que as respostas desses profissionais estão em consonância com os manuais de orientações técnicas que regulamentam as práticas nos CRAS e CREAS. As falas vão ao encontro do que diz o estudo realizado por Nascimento e Moraes (2019), no qual os psicólogos se utilizam das mesmas conceituações e estratégias para exemplificar suas práticas de trabalho, como o fortalecimento de vínculos, a superação das vulnerabilidades, a valorização das potencialidades dos usuários.

O CRAS por ser um órgão da Proteção Social Básica, oferta atendimentos e acompanhamentos familiares com o objetivo da prevenção das vulnerabilidades e o fortalecimento dos vínculos familiares e comunitários. Na Proteção Social Especial, esses acompanhamentos são realizados no CREAS devido ao agravamento das situações, que culminam com violações de direitos e rompimento de vínculos (Brasil, 2009, 2011a).

Essas orientações técnicas evidenciam a Assistência Social enquanto Política Pública de garantia de direitos e proteção social, e demonstram que é neste processo de conhecimento dos seus direitos que emerge a promoção da autonomia dos sujeitos.
Assim, o trabalho do psicólogo deve ser pautado pelo princípio da garantia de direitos (Brasil, 2011a; CFP, 2016).

A inserção da Psicologia na Assistência Social ainda é considerada um desafio para os profissionais que atuam nesse campo, em concordância com pesquisa realizada por Macedo et al. (2011), na qual referem que os participantes alertam para as dificuldades no dia a dia do trabalho. Estes apontam fatores como: uma formação com pouco investimento no campo das políticas públicas, alta rotatividade dos profissionais, precária estrutura física dos CRAS, escassez de recursos materiais e pessoais e baixo investimento do poder público no campo da Assistência Social.

A Psicologia também possui um compromisso ético, sobre o qual deve prevalecer um olhar crítico diante das realidades e do próprio trabalho, o que repercute nas relações de poder que se estabelecem neste contexto. A reflexão também deve ser incentivada nas intervenções junto aos usuários ao possibilitar que questionem suas condições de vida, e os meios para que possam ser ativos na transformação social que almejam (CFP, 2016). Os psicólogos entrevistados reforçaram essa ideia como se observa na fala destacada:

"O papel do psicólogo na Assistência Social, primeiramente tem o papel de emancipar as pessoas, transformação social [...]." (Psicólogo 3, comunicação pessoal).

Assim, a postura crítica e participativa deve permear a prática do psicólogo, para promover a autonomia e o protagonismo dos usuários, fortalecer os vínculos sociais e familiares, bem como, ressaltar suas potencialidades (CFP, 2016).

Ademais, de acordo com o Conselho Federal de Psicologia, existem algumas especificidades na atuação do psicólogo. Neste documento a relação entre Psicologia e a subjetividade é destacada, pois, compreende-se que a constituição do sujeito não é fragmentada de seu contexto social (CFP, 2016). Esse aspecto também surgiu nas entrevistas, muitos psicólogos apontaram dificuldades em definir sua atuação e reforçam enquanto especificidade profissional a escuta qualificada, a noção de subjetividade e o olhar contextual. 
"[...] eu acho que tem algumas peculiaridades que são da Psicologia sim, principalmente no sentido

de produção de subjetividade assim né, muito de estar pensando essas pessoas a partir dessas vulnerabilidades, que podem ser econômicas e pode ser racial, pode ser de gênero, pode ser né, diversos assim, eu acho que é muito o nosso papel, de tá pensando o quanto isso atravessa essas pessoas [...]." (Psicólogo 8, comunicação pessoal).

"[...] nosso papel né, diante de tudo isso que a gente às vezes não sabe bem qual é o lugar, é justamente essa escuta oferecer está escuta né, para as pessoas que vem aqui, que talvez vão em muitos serviços e não são nem olhadas [...]." (Psicólogo 2, comunicação pessoal).

Os profissionais para esclarecer sua atuação, enfatizam a dissociação entre o trabalho do psicólogo e do assistente social, no qual a Psicologia é relacionada ao sofrimento psíquico e, o Serviço Social à questão dos benefícios concedidos, como as cestas básicas, o Benefício de Prestação Continuada (BPC), e o Bolsa Família. Nascimento e Moraes (2019), também encontraram em sua pesquisa o desafio e a necessidade dos psicólogos em conceituar e distinguir o lugar que cada uma dessas profissões ocupa na Assistência Social, sendo enfatizada a insegurança dos trabalhadores e a falta de referenciais metodológicos.

Autores como Senra e Guzzo (2012) apontam que existe uma tensão na definição dos papéis e demandas de cada profissão, surgindo inúmeras discussões diante do cotidiano de trabalho. Essa divisão das demandas de acordo com a profissão, também é realizada pelos usuários dos serviços.

"Aqui nos serviços tem uma demanda grande de atendimento por vezes eu acho, ainda desse papel, ainda tem uma certa diferenciação, do que eu vou conversar com a psicóloga e o que eu vou conversar com o assistente social, dos usuários, né, e por vezes quando a gente fala que é psicóloga, vem muitas outras questões até do campo da saúde mental, que acabam chegando para nós [...]." (Psicólogo 6, comunicação pessoal).

De acordo com Oliveira (2012), Bock e Rechtman (2019), a fragmentação do trabalho é advinda do contexto histórico de formação dessas áreas, sendo que, a Psicologia fundou-se a partir de uma concepção positivista e individualizante. Em meados do século XIX a Psicologia começou a pensar sua metodologia de acordo com as ciências naturais, orientando-se pela mensuração e quantificação dos fenômenos psíquicos. Por meio de testagens psicológicas e categorização dos sujeitos, a questão da normalidade, objetividade e neutralidade subsidiou seu surgimento. Assim, o foco era em compreender a essência psicológica dos indivíduos em detrimento da sua cultura e contexto social (Reis \& Guareschi, 2013).

Os entrevistados enfatizaram que a atuação do psicólogo na Assistência Social não compreende atendimentos clínicos, pois são realizados atendimentos psicossociais, como se observa na fala do psicólogo abaixo. Esse atendimento se distingue da psicoterapia, pois, apesar de ter efeitos terapêuticos, possui outro viés teórico e prático (CFP, 2009).

"É que o trabalho aqui não é de psicoterapia, aqui o trabalho é acompanhamento psicossocial, isso é uma das coisas mais difíceis para nós psicólogos entendermos quando a gente entra." (Psicólogo 5, comunicação pessoal).

Contudo, destaca-se que essa opinião não é unanime entre os profissionais já que surgiu na fala de um profissional elementos que fazem pensar em uma prática clínica na Assistência Social. O psicólogo entrevistado refere a utilização de Avaliação Psicológica com crianças, principalmente aquelas envolvidas em situações de abuso sexual e, também menciona a utilização de genograma como uma técnica comum em sua atuação profissional.

"Utilizo algumas ferramentas, por exemplo, eu utilizo genograma, trabalho muito com genograma com todas familias que vem aqui, eu procuro entender o funcionamento e também captar qual é a rede de apoio [...]. E algumas para avaliação das crianças, eu utilizo umas ferramentas né, crianças menores eu uso HTP, crianças que sofreram abuso sexual [...]." (Psicólogo 5, comunicação pessoal).

Nos estudos de Macêdo, Alberto, Santos, Souza, \& Oliveira (2015), Ribeiro e Guzzo (2014) e Oliveira et al. (2014), constataram a prática de psicoterapia nos serviços da Assistência, principalmente nos CRAS. Esse fato está associado à formação acadêmica dos profissionais, uma vez que, a preparação teórica não abrange a ampla gama de possibilidades e práticas da Psicologia, predominando a ênfase na clínica e nos fenômenos psicológicos em detrimento das questões sociais (Yamamoto \& Oliveira, 2010; Motta \& Scarparo, 2013). 
Em recente estudo realizado por Bock e Rechtman (2019), com estudantes do último ano dos cursos de Psicologia do ano de 2014, foi possível identificar transformações no contexto de formação tradicional dos profissionais. As autoras afirmam o surgimento de um novo panorama formativo, mais voltado ao compromisso social da Psicologia, no qual emergem reflexões éticas, políticas e sociais.

Nesse sentido, existe uma certa ambivalência sobre a prática do psicólogo, ainda que definam seus papéis de acordo com a lógica da garantia de direitos na Assistência Social, na maioria das vezes, o que distingue a Psicologia é sua concepção positivista. Deste modo, muitas reflexões devem surgir diante da inserção do psicólogo nesse campo, pois, a imposição do saber psicológico tradicional ainda prevalece.

\section{Percepções dos Profissionais sobre os Usuários}

Esta categoria discorre sobre as concepções e julgamentos dos psicólogos frente aos indivíduos atendidos na Assistência Social, objetiva refletir a prática, verificar se prepondera a noção de sujeito autônomo ou, se vigora a visão assistencialista e normatizada em relação a esta Política. Nas entrevistas, foi possível verificar que há uma dissonância entre o desejo dos profissionais em promover autonomia e a promoção, de fato.

A maioria dos psicólogos salienta que sua atuação está relacionada a promoção de autonomia e capacidade crítica das pessoas, afirmam que buscam ressaltar suas potencialidades e percebem o usuário como um sujeito ativo. Para Teixeira (2010, p. 294), a noção de autonomia "envolve a capacidade de opinar, escolher, decidir e agir intencionalmente, mediante suportes oferecidos, capacidades construídas, situações refletidas [...]".

Nesta perspectiva, os entrevistados citam a necessidade de pensar junto com o usuário outras alternativas para as suas dificuldades e assim, construir sua autonomia. Este aspecto também é destacado na pesquisa de Pereira e Guareschi (2016), estas destacam que o papel do psicólogo envolve demonstrar caminhos e possibilidades.
"Então, eu enquanto psicóloga, vou tentar trabalhar isso, para criar junto com ele né, uma outra realidade, ou também ver, bom, tem todos esses problemas, mas qual é a potencialidade dessa pessoa, o que ela tem de potente dentro dela enquanto indivíduo para gente fortalecer isso." (Psicólogo 9, comunicação pessoal).

Segundo Lasta, Guareschi e Cruz (2012), a Psicologia enquanto ciência possui em seu escopo geral de atuação o incentivo a autonomia e controle dos sujeitos. Deste modo, um dos desafios dos psicólogos na Assistência Social é perceber os indivíduos de forma a transcender a normalização, para que não sejam definidos pela sua vulnerabilidade social, mas compreendidos enquanto sujeitos desejantes. Muitos psicólogos comentam que na realidade é difícil sair da lógica de detentores do saber, fato que é reforçado no cotidiano, tanto pelos próprios profissionais, quanto pelos usuários. Motta e Scarparo (2013) também ponderam sobre as dificuldades diante da busca pelo empoderamento dos indivíduos.

"Mas eu acho que a gente ainda tem esse olhar de que, ah, nós somos detentores do saber e eles são pessoas aí né, tipo, nós vamos determinar a vida dessas pessoas né." (Psicólogo 2, comunicação pessoal).

Foucault em sua obra "Estratégia, poder-saber", analisa a relação entre saber e poder, e afirma que os discursos dominantes, legitimados enquanto verdades absolutas, são produzidos a partir de práticas de poder sobre o outro. Destaca que "essas produções de verdades não podem ser dissociadas do poder e dos mecanismos de poder, ao mesmo tempo porque esses mecanismos de poder tornam possíveis, induzem essas produções de verdades [...]" (Foucault, 2003, p. 229).

Contudo, ainda que a realidade favoreça essa lógica do controle dos sujeitos, grande parte dos entrevistados refletiram sobre o compromisso ético e político da Psicologia, sobre o qual não deve prevalecer um saber dominante frente à vida dos sujeitos. Scisleski e Guareschi (2010) aponta o fato de que a Psicologia possui disposição para normatização, mas que também tem um potencial questionador das verdades absolutas e dos modos de subjetivação. 
"[...] porque não é nós que vamos determinar o que essa a família vai ter que fazer ou não né, essa família sim, vai ser ouvida, mas nós também vamos ter que ter intervenções né, conforme nossa perspectiva, a perspectiva da família, essa interlocução que é o âmago digamos." (Psicólogo 3, comunicação pessoal).

Na pesquisa também emergiu a concepção assistencialista, destacada na fala de um psicólogo, caracterizada enquanto dependência do usuário diante do serviço. Esse aspecto também foi encontrado nos estudos de Pereira e Guareschi (2014; 2016), que ressaltam a forte presença da cultura assistencialista ainda no contexto atual.

"Eu vejo que alguns criam até uma dependência como se a gente fosse escolher as coisas para vida deles, então também tem que ter esse cuidado assim né, de "olha, nós estamos aqui para te apoiar te dar suporte, orientações, mas tu vai partir das suas escolhas, tu vai poder seguir com autonomia, construindo a forma que tu vai lidar, viver a tua vida", e aí eles parecem que ficam nessa coisa de querer opinião, ou querem né, que a gente de alguma forma resolva ou veja como seguir. [...] Elas também criam de alguma forma uma visão de que elas podem se beneficiar de um atendimento, como

eu disse, a questão até de alimentos, outras coisas, $e$ muitas porque parece que elas precisam desse braço, assim tipo, assim né "me diz se eu estou fazendo certo, se as coisas estão indo como deveria né." (Psicólogo 2, comunicação pessoal).

Esta dependência é produzida socialmente, sendo que, a precariedade das condições sociais e econômicas de subsistência impõe aos sujeitos a necessidade em apelar aos serviços sociais. Ademais, os profissionais reproduzem práticas que reforçam essa dependência, ao desqualificar os sujeitos, desconsideram sua autonomia (Pereira \& Guareschi, 2014).

De acordo com Cruz e Guareschi (2012b) existe um conflito entre o sujeito de direito e o sujeito da caridade na Assistência Social, relacionado a concessão dos benefícios socioassistenciais. Tal pensamento é destacado por Nascimento e Moraes (2019), ao demonstrarem a visão assistencialista dos psicólogos e usuários dos serviços em relação a distribuição de cestas básicas. O assistencialismo é reproduzido por discursos dominantes que marcaram o surgimento da Psicologia. Assim, permanecem questionamentos, como se os benefícios não fossem um direito social.
Conforme Pereira e Guareschi (2014), a cesta básica é o meio pelo qual os indivíduos acessam o seu direito à alimentação. Portanto, verificou-se que há uma ambiguidade nos discursos dos entrevistados, uma vez que, ao mesmo tempo que reforçam a importância de promover a autonomia dos indivíduos atendidos, no cotidiano de trabalho existem resquícios das ideias assistencialistas, em que o sujeito é passivo diante da sua vida. Entretanto, a maioria dos profissionais questiona suas práticas, fato que é fundamental para que mudanças possam ser efetivadas, tanto nas suas concepções, como no exercício da sua profissão.

\section{Percepções dos Profissionais sobre o Trabalho}

O CFP (2016) estabelece enquanto princípio do trabalho no SUAS a interdisciplinaridade e a intersetorialidade, e foca na necessidade de um trabalho em equipe articulado com os demais setores de Proteção Social. Deste modo, prima-se pela complementação e difusão do conhecimento, superando a lógica da fragmentação do trabalho. No entanto, a prática nos serviços de Assistência Social encontra muitos desafios, geralmente ocorre uma barreira entre a realidade do trabalho e os parâmetros técnicos.

Esta categoria visa discutir sobre o modo como os profissionais entrevistados percebem em seu cotidiano a organização e o fluxo de trabalho, suas dificuldades, críticas e desejos, bem como, se há um trabalho interdisciplinar e intersetorial. De acordo com os relatos, existem muitas angústias em relação ao trabalho, pois, na maioria dos serviços, não é possível realizar atendimentos em conjunto, discussões de casos e pensar sobre a prática profissional. Pelo contrário, o cenário é de um trabalho fragmentado e quantitativo, os profissionais são cobrados pela Gestão Política por dar conta das demandas e por produtividade. Assim, o que pode-se constatar nestes municípios foi que o trabalho interdisciplinar e intersetorial ocorre somente em situações mais complexas, o que emerge da falta de recursos para tanto e aponta um trabalho alienado.

Neste contexto, por meio da intersetorialidade, se almeja a efetivação de uma rede de proteção social, pois, os órgãos das Políticas Públicas devem articular sua atuação e, promover o acesso dos usuários a todos os serviços a que têm direito (CFP, 2016). Os entrevistados mencionaram encaminhamentos e contatos com diversas instituições, principalmente voltadas à saúde e educação, fato também verificado no estudo de Oliveira et al. (2014). 
Outra estratégia mencionada para efetivação da intersetorialidade são as reuniões de rede no território, realizadas nos CRAS, das quais participam diferentes profissionais para discutir sobre as situações mais complexas que estão em atendimento. Cabe ressaltar que a intersetorialidade apenas se efetiva quando os serviços e os profissionais estão comprometidos em realizar um trabalho em comum, priorizando a comunicação e transcendendo barreiras (Carlson \& Pinheiro, 2013).

"Se tu for pensar o modo como a Assistência Social trabalha, ela é uma política absurdamente articuladora. Então, a gente tem contato muito estreito com algumas instituições, algumas escolas, o Conselho Tutelar, com agentes de saúde do interior, com postos de saúde, com a própria Secretaria de Educação." (Psicólogo 1, comunicação pessoal).

Para Gattás e Furegato (2006) a interdisciplinaridade permite que o profissional conheça e descubra diferentes realidades. Conforme Motta e Scarparo (2013), para efetivação deste pensamento, é preciso uma atuação na qual ocorram reuniões e discussões contínuas entre a equipe, para ponderar as particularidades das demandas. Nesta pesquisa, percebe-se o desejo dos psicólogos em atuar de forma interdisciplinar, pois, muitos relatam as tentativas para tanto, ressaltam a necessidade de reuniões, discussões e atendimentos conjuntos, entre psicólogo e assistente social. Porém, essas tentativas são frustradas, assim como reforça Salgado (2015) em sua pesquisa, não há um trabalho interdisciplinar, devido aos inúmeros desafios cotidianos.

"A equipe, eu acho muito unida, muito próximo e tem uma interdisciplinaridade tem, na medida do possível, poderia ter mais quem sabe, como eu te disse anteriormente né, poderia trabalhar mais juntos no atendimento, poderíamos discutir mais os casos que a gente não está conseguindo discutir." (Psicólogo 3, comunicação pessoal).

Os desafios enfrentados para a efetivação do trabalho em equipe e na construção de uma rede são muitos e, vão desde a falta de comunicação e capacitação dos profissionais, até a precarização das políticas públicas. (Neves, Castro, Hayeck, \& Cury, 2010). Tal precarização e fragmentação dos saberes e práticas do psicólogo, são destacadas pelos autores como consequência da falta de recursos, investimentos e valorização da Política de Assistência Social. (Brandolt et al., 2020; Pauli, Traesel \& Siqueira, 2019).
Os entrevistados reforçam a grande demanda de trabalho, que acaba por priorizar a quantidade em detrimento da qualidade, a necessidade de recursos humanos e de capacitação dos profissionais, dificuldades também evidenciadas nas pesquisas de Teixeira (2010), Nascimento e Moraes (2019) e Brandolt et al. (2020).

"Porque eu acho que o trabalho, ele acaba atropelando assim, e a gente tem que estar sempre batalhando por um espaço de parar e pensar na organização de trabalho, $e$ de pensar sobre o que a gente está fazendo né." (Psicólogo

8, comunicação pessoal).

A Norma Operacional Básica de Recursos Humanos do Sistema Único de Assistência Social- NOB-RH/ SUAS (Brasil, 2011b), que regulamenta a Gestão do Trabalho no SUAS, determina a capacitação permanente dos trabalhadores e visa ampliar seus conhecimentos de acordo com as necessidades técnicas e práticas de atuação. Segundo Ribeiro, Paiva, Seixas e Oliveira (2014) as demandas da Assistência Social são diversas e complexas, trazem no seu bojo temáticas que não foram debatidas pelos profissionais ao longo de sua formação profissional, como violência contra mulher e abuso sexual.

No contexto geral da Assistência Social, a organização de trabalho ainda possui muitas falhas e dificuldades, no entanto, os profissionais refletem de forma crítica diante disso e, tentam buscar estratégias para melhorias. A atuação interdisciplinar, intersetorial e a capacitação constituem momentos e espaços de trocas e diálogo, ricos para os profissionais e principalmente, para os usuários dos serviços, já que, estes contribuem para uma maior resolutividade no atendimento aos mesmos.

\section{Atravessamentos no Trabalho}

Essa categoria de analise define que "atravessamento significa que qualquer instituição é sempre atravessada por outras instituições [...]", (Junges, Selli, Soares, Fernandes, \& Schreck, 2009, p. 938), e reflete sobre alguns dos atravessamentos presentes no trabalho do psicólogo na Assistência Social. Nas narrativas dos entrevistados o maior desafio que estes sentem em seu dia a dia, é em como dar conta da quantidade de demandas advindas de instituições e atores como o Poder Judiciário, os usuários, os profissionais da rede, e a Gestão Política. 
O Poder Judiciário foi dos atravessamentos mais citados como órgão que demanda e regula o trabaIho dos profissionais continuamente. A demanda por respostas rápidas, com curtos prazos sobrecarrega os serviços, principalmente os CREAS, serviço em que é mais frequente os encaminhamentos e solicitações feitas pelo Judiciário. Ademais, existe uma burocracia enorme neste sentido, que corresponde a uma troca de informação rígida via ofícios e relatórios, ao invés de um contato estreito e articulado.

"Atualmente, com esses três órgãos aí, MP, Defensoria e Juizado, é uma troca de informação via papel muito mecânica, e muitas vezes, assim, eles usam a Assistência como receptor de demanda e como um emissor de informação." (Psicólogo 1, comunicação pessoal)

Essa forma de trabalho do Judiciário se associa às práticas de governo da vida de que fala Foucault (2003), pois, é uma instituição que visa o controle dos indivíduos. O autor salienta que "o Estado que garante a segurança é um Estado que está obrigado a intervir em todos os casos em que a trama da vida cotidiana é rompida por um acontecimento singular, excepcional" (Foucault, 2010, p. 172). Deste modo, na maioria das vezes, por meio da Assistência Social, esse sistema faz com que as pessoas se sujeitem, obrigando-as a estar num determinado espaço, por exemplo, este aspecto é visível nas falas dos profissionais pesquisados,

"[...] a maioria das famílias e indivíduos vem por obrigação, digamos assim né, por determinação do judiciário, eles vêm porque são obrigados." (Psicólogo 3, comunicação pessoal)

Portanto, o Judiciário representa o biopoder, atua sobre a população por meio da biopolítica de Assistência Social. Conforme Foucault (2005) a biopolítica constitui o meio pelo qual o biopoder alcança a população. Nessa perspectiva, a Política de Assistência Social é uma estratégia sutil de regulamentar o governo das populações, ainda que possua como finalidade o bem-estar social. Desta forma, o trabalho do psicólogo na assistência pode se caracterizar como coercitivo ou emancipatório. Por isso, é preciso refletir sobre as práticas realizadas de forma ética. Faz-se mister resistir a todo momento as demandas que incidem em um trabalho burocrático e disciplinar. (Lasta, 2015; Macedo \& Dimenstein, 2009; Pereira \& Guareschi, 2014).
Além do Poder Judiciário, outro atravessamento citado pelos profissionais é o funcionamento da Gestão Política dos serviços, pois este influencia diretamente sobre o modo de organização do trabalho. Na pesquisa realizada por Pauli et al. (2019), também foi possível identificar as dificuldades advindas da gestão precária, que desconsidera as diretrizes que orientam as práticas de trabalho, desqualifica os trabalhadores, bem como os usuários. Os profissionais perdem autonomia, pois suas ideias não são consideradas, ocorre desta forma uma centralização do trabalho em detrimento da descentralização que é postulada pela Política de Assistência Social (Teixeira, 2010).

\section{"[...] da forma como tá acontecendo essa gestão assim,} de busca de produção, de produção, que daí estimula essa coisa bem de fábrica assim, a impressão que me dá." (Psicólogo 2, comunicação pessoal).

Além disso, neste cenário repleto de desafios diários, muitas demandas ultrapassam a abrangência do serviço. Usuários e profissionais da rede de atendimento desconhecem o papel do psicólogo nesta Política, produzem uma demanda excessiva à Assistência Social, principalmente no que se refere a atendimentos clínicos e individuais. Oliveira et al. (2014) também destacam essa grande demanda de atendimento individual advinda de outros setores, como saúde e educação, para os serviços de assistência. Aspecto que foi observado nos discursos dos profissionais desta pesquisa:

"[...] só que lá fora, as pessoas que não conhecem o CREAS, essas pessoas têm dificuldade, então assim, vem muitos casos para cá com essa demanda, faça acompanhamento psicossocial, as vezes até fala em psicoterapia, avaliação psicológica né." (Psicólogo 5, comunicação pessoal)

Contudo, é preciso considerar como essas demandas são produzidas. Na ótica da Análise Institucional, a demanda sempre é provocada, não é espontânea, ou seja, ela é produzida a partir da oferta dos serviços. O contexto social interfere nessa demanda, pois, no momento em que um serviço não consegue suprir o que está sendo demandado, essa demanda atinge outro serviço (Baremblitt, 2002). É visível o quanto essa conceituação se aplica a Política de Assistência Social, pois, existem muitas falhas e descontinuidades na rede de atendimento à população em geral, principalmente quanto aos serviços de saúde e atendimento psicológico. 


\section{Considerações Finais}

A pesquisa objetivou compreender uma prática que ainda é recente, como a Psicologia está inserida na Política de Assistência Social e, de que forma se dá a atuação dos psicólogos neste contexto. Os resultados encontrados no decorrer das entrevistas indicam que a maioria dos psicólogos norteia a sua atuação a partir das orientações técnicas da Política de Assistência Social, bem como das normativas estabelecidas pelo do Conselho Federal de Psicologia. Todavia os entrevistados ainda possuem dificuldades em definir as particularidades de sua profissão, referem a necessidade de distingui-la do Serviço Social a partir de uma concepção tradicional da Psicologia, na qual o psicólogo é percebido enquanto aquele que lida com o sofrimento de forma individual. Salienta-se que este estudo se refere a um contexto específico, que não pode ser generalizado e ocorre no interior do sul do país em dois municípios.

A atuação na Assistência Social é concebida por meio da lógica da autonomia, empoderamento e fortalecimento dos sujeitos, para que acessem seus direitos como cidadãos, sujeitos de direitos. No entanto, na prática, a promoção de autonomia é algo muito complexo e, construir caminhos e possibilidades junto ao usuário requer um trabalho contínuo, de reflexão mútua, uma vez que, tanto os profissionais, como os próprios usuários possuem uma visão assistencialista, que os enquadra enquanto sujeitos de caridade, passivos.

Alguns psicólogos permeiam sua atuação a partir da noção de sujeitos que precisam ser ajudados, guiados pela mão para acessar seus direitos, pois a realidade favorece essa percepção. Contudo, grande parte deles reflete criticamente diante de seu trabalho, compreende que é preciso construir espaços para pensar além e, modificar sua prática. Nesta perspectiva, a Política de Assistência Social poderá ser efetivada enquanto uma política que potencializa sujeitos de direitos.

A inovação desta pesquisa se refere justamente a esse aspecto, trazer as percepções dos profissionais sobre os usuários, uma vez que, existem poucos estudos nesta perspectiva, a maioria das pesquisas relatam as representações dos usuários sobre os psicólogos e os serviços. Cabe ressaltar que o momento de pesquisa possibilitou a reflexão dos profissionais, pois, ao mesmo tempo que refletiam sobre suas práticas, questionavam e apontavam que faltam espaços e momentos para pensar e avaliar seu trabalho. A limitação do estudo foi não ter analisado a percepção da gestão sobre o trabalho do psicólogo, o que poderia nos dar mais elementos para reflexão e aprofundamento da temática, fica como sugestão para outros estudos.

Observou-se que há uma demanda excessiva, que sobrecarrega todos os locais pesquisados e, enquanto os profissionais estiverem atendendo a todas as demandas que chegam, do Poder Judiciário, da gestão, sem espaço para reflexão sobre as formas de organização do trabalho, essa continuidade na produção de demandas não se esgotará. A Psicologia, enquanto ciência e área de conhecimento, possui o compromisso ético de transformação social, deve refletir e fomentar as problematizações diante dos saberes que produzem modos de subjetivação.

\section{Contribuições das autoras}

Ambas as autoras participaram da concepção, delineamento, interpretação e análise dos dados, interpretação dos resultados e redação do artigo científico.

\section{Conflitos de interesses}

Nenhum conflito financeiro, legal ou político envolvendo terceiros (governo, empresas e fundações privadas, etc.) foi declarado para nenhum aspecto do trabalho submetido (incluindo, mas não se limitando a subvenções e financiamentos, participação em conselho consultivo, desenho de estudo, preparação de manuscrito, análise estatística, etc.).

\section{Referências}

Bardin, L. (2004). Análise de conteúdo (3a ed.). Lisboa: Edições 70.

Baremblitt, G. (2002). Compêndio de Análise Institucional e Outras Correntes: teorias e práticas (5a ed.). Belo Horizonte: Instituto Félix Guattari.

Bock, A. M. B., \& Rechtman, R. (2019). Formação do Psicólogo para a Realidade Brasileira: Identificando Recursos para Atuação Profissional. Psicologia: Teoria e Pesquisa, 35(e3551), 1-10. Recuperado de https://www.scielo. br/pdf/ptp/v35/1806-3446-ptp-35-e3551.pdf. doi: 10.1590/0102.3772e3551 
Brandolt, C. R., Santos, S. S., Coelho-Lima, F., \& Motta, R. F. (2020). Psicologia na Assis $\neg$ tência Social e a Atuação por via de Contratos Terceirizados. Revista Psicologia: Organizações e Trabalho, 20(2), 1033-1039. Recuperado de http://pepsic. bvsalud.org/pdf/rpot/v20n2/v20n2a10.pdf. doi: 10.17652/ rpot/2020.2.17987

Brasil. Secretaria Nacional de Assistência Social. (2009). Orientações técnicas: centro de referência de assistência social- CRAS. Brasília: Secretaria Nacional de Assistência Social. Recuperado de http://www.mds.gov.br/ webarquivos/publicacao/assistencia_social/Cadernos/ orientacoes_Cras.pdf

Brasil. Secretaria Nacional de Assistência Social. (2011). Orientações técnicas: centro de referência especializado de assistência social- CREAS. Brasília: Secretaria Nacional de Assistência Social. Recuperado de http://aplicacoes.mds. gov.br/snas/documentos/04-caderno-creas-final-dez..pdf

Brasil. Secretaria Nacional de Assistência Social. (2011). NOBRH Anotada e Comentada. Brasília: Secretaria Nacional de Assistência Social. Recuperado de https://aplicacoes.mds. gov.br/sagirmps/ferramentas/docs/Projeto_04_046_2011_ Produto_2.pdf

Carlson, A. C. R, \& Pinheiro, L. S. (2013). Práticas intersetoriais: novos desafios postos aos psicólogos na atual política de assistência social. In L. R. Cruz, L. Rodrigues, \& N. M. F. Guareschi (Eds.), Interlocuções entre a psicologia e a política nacional de assistência social (pp. 103-17). Santa Cruz do Sul, RS: EDUNISC.

Conselho Federal de Psicologia. (2009). Serviço de Proteção Social a Crianças e Adolescentes Vítimas de Violência, Abuso e Exploração Sexual e suas Famílias: referências para a atuação do psicólogo. Brasília: Conselho Federal de Psicologia. Recuperado de https://site.cfp.org.br/wpcontent/uploads/2009/10/CREPOP_Servico_Exploracao_ Sexual.pdf

Conselho Federal de Psicologia. (2012). Referências técnicas para prática de psicólogas(os) no Centro de Referência Especializado de Assistência Social- CREAS. Brasília: Conselho Federal de Psicologia. Recuperado de http://www.crpsp. org.br/portal/comunicacao/artes-graficas/arquivos/2013CREPOP-CREAS.pdf

Conselho Federal de Psicologia. (2016). Nota técnica com parâmetros para atuação das (os) profissionais de psicologia no âmbito do Sistema Único de Assistência Social (SUAS). Brasília: Conselho Federal de Psicologia. Recuperado de https://site.cfp.org.br/wp-content/uploads/2016/12/Notate\%CC\%81 cnica-web.pdf

Cruz, L. R., \& Guareschi, N. M. F. (2012a). A constituição da Assistência Social como política pública: interrogações à psicologia. In L. R. Cruz, \& N. M. F. Guareschi (Eds.), Políticas Públicas e Assistência Social: diálogo com as práticas psicológicas (3a ed., pp. 13-40). Petrópolis, RJ: Vozes.
Cruz, L. R., \& Guareschi N. M. F. (2012b). Articulações entre a Psicologia Social e as políticas públicas na Assistência Social. In L. R. Cruz, \& N. M. F. Guareschi (Eds.), O psicólogo e as políticas públicas de assistência social (pp. 15-34). Petrópolis, RJ: Vozes.

Foucault, M. (2010). Repensar a Política (Coleção Ditos \& Escritos VI). Rio de Janeiro: Forense Universitária.

Foucault, M. (2005). Em defesa da sociedade: curso dado no Collège de France (1975-1976). São Paulo: Martins Fontes.

Foucault, M. (2003). Estratégia, poder-saber (Coleção Ditos \& Escritos VI). Rio de Janeiro: Forense Universitária.

Gattás, M. L. B., \& Furegato, A. R. F. (2006). Interdisciplinaridade: uma contextualização. Acta Paulista de Enfermagem, 19(3), 323-327. Recuperado de https://www.scielo.br/ scielo.php?pid=S0103-21002006000300011\&script=sci_ abstract\&tlng=pt. doi: 10.1590/S0103-21002006000300011

Gomes, N. S., \& Gonçalves, S.M.M. (2018). A psicologia na assistência social: considerações sobre o percurso histórico deste "novo" campo. Revista Mosaico, 9(1), 02-09. Recuperado de http://editora.universidadedevassouras. edu.br/index.php/RM/article/view/1225/pdf. doi: 10.21727/rm.v9i1.1225

Silveira, D. T., \& Córdova, F. P. (2009). A Pesquisa Científica. In T. E. Gerhardt, \& D. T. Silveira (Eds.). Métodos de pesquisa (pp. 31-42). Porto Alegre: Editora da UFRGS.

Scisleski, A. C. C., \& Guareschi, N. M. F. (2010). Governando a vida: (pro)vocações para a psicologia. In N. M. F. Guareschi, A. C. C. Scisleski, C. Reis, G. Dhein, \& M. A. Azambuja (Eds.). Psicologia, Formação, Políticas e Produção em Saúde (pp. 167-83). Porto Alegre: EDIPUCRS.

Junges, J. R., Selli, L., Soares, N. A., Fernandes, R. B. P., \& Schreck, M. (2009). Processos de trabalho no Programa Saúde da Família: atravessamentos e transversalidades. Revista da Escola de Enfermagem da USP, 43(4), 937-944. Recuperado de https://www.scielo.br/scielo.php?script=sci_ abstract\&pid=S0080-62342009000400028\&lng=en\&nrm=i so\&tlng=pt. doi: $10.1590 / 50080-62342009000400028$

Lasta, L. L. (2015). Políticas de Assistência Social no Brasil: o governo da vida pela proteção e inclusão social (Tese de Doutorado). Universidade Federal do Rio Grande do Sul, Porto Alegre, RS, Brasil. Recuperado de http://hdl.handle. net/10183/141505

Lasta, L. L., Poli, M. C., Scisleski, A., Hillesheim, B., Susin, L., Guareschi, N. M. F., ... Warpechowski, M. B. (2012). A Psicologia e os Centros de Referência em Assistência Social: problematizações pertinentes. In L. L. Lasta, \& N. M. F. Guareschi (Eds.). O psicólogo e as políticas públicas de assistência social (pp. 52-65). Petrópolis, RJ: Vozes. 
Macedo, J. P., \& Dimenstein, M. (2009). Psicologia e a produção do cuidado no campo do bem-estar social. Psicologia \& Sociedade, 21(3), 293-300. Recuperado de https://www. scielo.br/pdf/psoc/v21n3/a02v21n3.pdf. doi: $10.1590 /$ s0102-71822009000300002

Macedo, J. P., Sousa, A. P., Carvalho, D. M., Magalhães, M. A., Sousa, F. M. S., \& Dimenstein, M. (2011). O psicólogo brasileiro no Suas: quantos somos e onde estamos?. Psicologia em Estudo, 16(3), 479-489. Recuperado de https://www.scielo.br/pdf/pe/v16n3/v16n3a15.pdf. doi: 10.1590/S1413-73722011000300015

Macêdo, O. J. V., Lima, C. M. P. D., Brito, F. H. S., Souza, J. N. P., Souza, N. K., M., Souza, S. P., ... Dias, S. G. (2018). Atuação dos profissionais de Psicologia no CRAS do interior de Paraíba. Trends Psychol, 26(2), 1083-1097. Recuperado de https://www.scielo.br/pdf/tpsy/v26n2/2358-1883tpsy-26-02-1083.pdf. doi: 10.9788/tp2018.2-20pt

Macêdo, O. J. V., Alberto, M. F. P., Santos, D. P., Souza, G. P., \& Oliveira, V. S. (2015). Ações do Profissional de Psicologia no Centro de Referência da Assistência Social. Psicologia: Ciência e Profissão, 35(3), 809-823. Recuperado de https://www.scielo.br/scielo.php?pid=S141498932015000300809\&script=sci_abstract\&tlng=pt. doi: 10.1590/1982-3703001632013

Motta, R. F., \& Scarparo, H. B. K. (2013). A psicologia na assistência social: transitar, travessia. Psicologia \& Sociedade, 25(1), 230-239. Recuperado de https://bit.ly/3jyLHRO. doi: 10.1590/S0102-71822013000100025

Nascimento, I. L., \& Moraes, T. D. (2019). Atuação de psicólogas na assistência social: relações entre gênero profissional e saúde. Laboreal, 15(2), 1-22. Recuperado de http://www. scielo.mec.pt/pdf/lab/v15n2/v15n2a10.pdf. doi: $10.4000 /$ laboreal.15090

Neves, A. S., Castro, G. B., Hayeck, C. M., \& Cury, D. G. (2010). Abuso sexual contra a criança e o adolescente: reflexões interdisciplinares. Temas em Psicologia, 18(1), 99-111. Recuperado de http://pepsic.bvsalud.org/pdf/tp/v18n1/ v18n1a09.pdf

Oliveira, I. F. (2012). Os desafios e limites para a atuação do psicólogo no Suas. In L. R. Cruz, \& N. M. F. Guareschi (Eds.). O psicólogo e as políticas públicas de assistência social (pp. 35-51). Petrópolis, RJ: Vozes.

Oliveira, I. F., Oliveira, N. L. A., Nascimento, M. N. C., Araújo, R. L., Coelho-Lima, F., \& Amorim, K. M. O. (2014). Atuação dos psicólogos nos CRAS do interior do RN. Psicologia \& Sociedade, 26(spe2), 103-112. Recuperado de https://bit. ly/3jvMYbs. doi: 10.1590/S0102-71822014000600011
Pauli, C. G., Traesel, E. S., \& Siqueira, A. C. (2019). Precarização do Trabalho de Psicólogos Temporários no CREAS. Psicologia: Ciência e Profissão, 39(e188301), 1-13. Recuperado de https://www.scielo.br/pdf/pcp/v39/1982-3703-pcp39-e188301.pdf. doi: 10.1590/1982-3703003188301

Pereira, V. T., \& Guareschi, P. A. (2014). Representações sociais da Psicologia sobre os usuários do CRAS: culpabilização dos sujeitos em situação de vulnerabilidade social. Diálogo, (26), 9-24. Recuperado de https://revistas. unilasalle.edu.br/index.php/Dialogo/article/view/1626. doi: $10.18316 / 1626$

Pereira, V. T., \& Guareschi, P. A. (2016). O CRAS em relação: profissionais e usuários(as) em movimento. Fractal: Revista de Psicologia, 28(1), 102-110. Recuperado de https://www.scielo.br/scielo.php?pid=S198402922016000100102\&script=sci_abstract\&tlng=pt. doi: 10.1590/1984-0292/1153

Reis, C., \& Guareschi, N. M. F. (2013). A formação em psicologia: desafios para a inserção profissional nas políticas públicas de saúde. In A. M. C. Ximenes, C. Reis, \& R. W. Oliveira (Eds.). Entre Garantia de Direitos e Práticas Libertárias (pp. 257-280). Porto Alegre, RS: Conselho Regional de Psicologia do Rio Grande do Sul.

Ribeiro, A. B., Paiva, I. L., Seixas, P. S., \& Oliveira, I. M. F. F. (2014). Desafios da atuação dos psicólogos nos CREAS do Rio Grande do Norte. Fractal: Revista de Psicologia, 26(2), 461-478. Recuperado de https://www.scielo.br/ scielo.php?pid=S1984-02922014000200461\&script=sci_ abstract\&tIng=pt. doi: 10.1590/1984-0292/421

Ribeiro, M. E., \& Guzzo, R. S. L. (2014). Psicologia no Sistema Único de Assistência Social (SUAS): reflexões críticas sobre ações e dilemas profissionais. Pesquisas e Práticas psicossociais, 9(1), 83-96. Recuperado de http://www.seer.ufsj.edu.br/ index.php/revista_ppp/article/view/837/651

Salgado, F. F. (2015). O trabalho interdisciplinar na assistência social: análise da experiência em um CRAS de NiteróiRJ. Seminário Nacional de Serviço Social, Trabalho e Política Social - Universidade Federal de Santa Catariana, Florianópolis, SC, Brasil. Recuperado de https:// repositorio.ufsc.br/bitstream/handle/123456789/180724/ Eixo_3_037.pdf?sequence=1\&isAllowed=y

Senra, C. M., \& Guzzo, R. S. (2012). Assistência Social e Psicologia: sobre as tensões e conflitos do psicólogo no cotidiano do serviço público social. Psicologia \& Sociedade, 24(2), 293-99. Recuperado de https://www.scielo.br/scielo. php?pid=S0102-71822012000200006\&script=sci_ abstract\&tlng=pt. doi: 10.1590/S010271822012000200006 